\title{
Phylogeny of the genus Hegeter (Tenebrionidae, Coleoptera) and its colonization of the Canary Islands deduced from Cytochrome Oxidase I mitochondrial DNA sequences
}

\author{
CARLOS JUAN*, PEDRO OROMI $\uparrow$ \& GODFREY M. HEWITT \\ Population Biology Sector, School of Biological Sciences, University of East Anglia, Norwich NR4 7TJ, U.K. and \\ $\dagger$ Departamento de Zoología, Facultad de Biología, Universidad de La Laguna, Tenerife, Spain
}

\begin{abstract}
The genus Hegeter comprises 23 species of darkling beetles (Tenebrionidae) endemic to the Macaronesian archipelagos, with 21 of them exclusive to the Canary Islands. We have sequenced 438 bp of the mitochondrial Cytochrome Oxidase I gene in 17 species (24 taxa) of Canarian Hegeter. Estimates of nucleotide composition, transition/transversion ratios and nucleotide change frequencies are very similar to those found in another tenebrionid Canarian genus Pimelia, indicating that similar molecular mechanisms are driving the sequence evolution. The sequence variation found allows phylogenetic analyses of the genus and the deduction of colonization patterns. These involve sequential island invasion with more rapid establishment and radiation than found in the related beetles of the genus Pimelia.
\end{abstract}

Keywords: beetle, Canary Islands, colonization, Cytochrome Oxidase I, DNA sequence, phylogeny.

\section{Introduction}

The Canary archipelago appears to be an excellent model for studying colonization and speciation processes. Endemic Canarian lizards and beetles have recently been used to construct molecular phylogenies and deduce sequential interisland colonizations; these can then be compared with the geological age of the islands (Thorpe et al., 1993, 1994; Juan et al., 1995). Several independent datings strongly support a decrease in the age of the islands from east to west, probably related to the volcanic activity produced by a propagating fracture zone originating from the Atlas mountains in North Africa (Anguita \& Hernan, 1975). The maximum datings range from $20 \mathrm{My}$ for Fuerteventura to fewer than $1 \mathrm{My}$ for Hierro (Fig. 1) (Anguita \& Hernan, 1975). Variation of mitochondrial Cytochrome Oxidase I (CO I) DNA sequences (Juan et al., 1995) of darkling beetles of the genus Pimelia

*Correspondence: Department de Biologia Ambiental, Universitat de les Illes Balears, 07071 Palma de Mallorca, Spain. produces a phylogeny which suggests the sequence in which they colonized the Canary Islands. This comprises an ancestral species, related to the extant $P$. lutaria endemic to Fuerteventura and Lanzarote, which probably colonized Tenerife. Representatives of its radiation on these islands in turn colonized Gran Canaria and Gomera. From the latter, relatively recent colonizations populated La Palma, and finally from here Hierro was colonized. This pattern fits well with the sequential formation and age of the islands, i.e. as they emerged they were colonized from the closest older island, with the exception of Gran Canaria which is older than Tenerife and should be colonized first according to this model. Clearly, factors like extinctions and secondary colonizations may modify the original simple overall pattern.

The genus Hegeter comprises darkling beetles endemic to the Macaronesian islands, with 22 species in the Canaries, one species in the Salvagem Islands and another species, $H$. tristis, distributed from the Azores to Cabo Verde including the Canaries and the Saharan coast (Español, 1957a,b; 


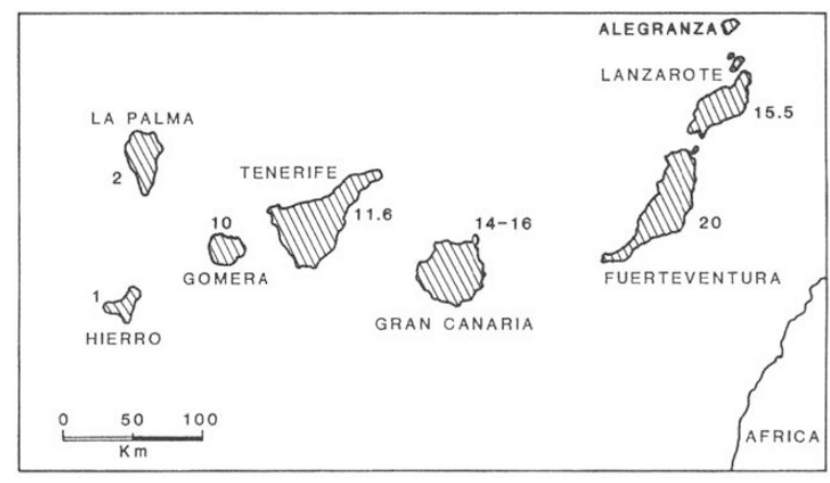

Fig. 1 Map of the Canary archipelago. Numbers refer to the proposed maximum geological ages estimated for the main islands (My) (Anguita \& Hernan, 1975).

Oromí, 1982a). The genus has therefore experienced a process of considerable diversification and speciation in the Canary archipelago. All but three species on the Canaries are endemic to a single island; $H$. tristis is present in all main islands except Gran Canaria, where $H$. grancanariensis occupies the niche of the former. Hegeter amaroides is found in the western islands, Tenerife, Gomera and Hierro, but not La Palma in which another vicariant species, $H$. glaber, is present. Hegeter politus is present in Fuerteventura, Lanzarote and the islets nearby. The bigger islands of Fuerteventura, Gran Canaria and Tenerife show the highest number of exclusive endemisms, with three, six and seven, respectively, whereas the younger, smaller and more remote $\mathrm{La}$ Palma and Hierro have one endemic species on the former and none on the latter (Table 1).

The beetles of this genus are flightless saprophagous insects adapted to different habitats in the islands. Most are xerophilic and present at low or medium altitude, but some are present in the high altitude volcanic zones, e.g. H. tenuipunctatus and $H$. lateralis of Tenerife (Table 1). Español (1957a,b) revised the taxonomy of the group dividing the genus into three subgenera: Hegeter s. str. Latr., Pseudotalphila Reitt. and Homalapipleurus Españ. according to the presence or absence of stridulatory apparatus and epistome morphology. The subgenus Hegeter s. str. includes all the species which occur in the western and central islands (Gran Canaria, Tenerife, Gomera, La Palma and Hierro), whereas the other two subgenera are exclusively of the eastern islands (Fuerteventura and Lanzarote). The larger subgenus Hegeter s. str. has been divided into five species groups (see Table 1) according to the different morphological characters considered in the taxonomy of these beetles. Some of the species groups, in particular the brevicollis complex of Tenerife, have been reported to show gradual transitions in the morphological characteristics and remarkable variability of the different taxa.

In this study, we have collected for a molecular phylogenetic analysis 17 Hegeter Canarian species (Table 1), three of them including representatives of the taxa present in several islands; $H$. amaroides and $H$. politus from all their island distribution and $H$. tristis from Hierro and the islet of Alegranza near Lanzarote. Also, sequences were obtained for $H$. politus (Fuerteventura) and $H$. brevicollis (Tenerife) from three and two individuals, respectively. In total, DNA sequences corresponding to at least $438 \mathrm{bp}$ of the COI gene have been determined for 27 different Hegeter haplotypes. Also, two species from different genera have been sequenced and tentatively used as outgroups in the phylogenetic analysis. One is the morphologically related genus Tentyria from Mallorca (Balearic Islands) and the other is a Canarian Pimelia from a previous study. Both species belong to the same subfamily (Pimeliinae, sensu Doyen, 1972), and to the family Tenebrionidae, as does the genus Hegeter. The sequences obtained have been used to construct gene phylogenies and the results compared to those obtained for the Canarian Pimelia in order to look for general patterns of DNA variation and colonization of the Canaries by tenebrionids.

\section{Materials and methods}

\section{Sampling}

The Hegeter species were collected from the Canary Islands as listed in Table 1 (a full list of the collection localities can be provided on request). Single individuals were used for amplification and sequencing, except for $H$. politus, $H$. tristis, $H$. amaroides and $H$. brevicollis, in which more than one individual was separately analysed. The sequences used for comparative purposes are those of Tentyria schaumi and Pimelia laevigata. The insects were preserved in absolute ethanol or sent alive by mail to the laboratory.

\section{DNA preparations, $P C R$ amplifications and sequencing}

DNA was extracted from the heads and thoraces of individual beetles by standard phenol extraction and ethanol precipitation. Two different portions of the mitochondrial COI were used for PCR amplifications. The oligonucleotides used to amplify fragment 
Table 1 List of Hegeter species, their taxonomic groupings (Español 1957a,b), island distribution, habitat and number of individuals used in this study with their island provenance

\begin{tabular}{|c|c|c|c|}
\hline Species \& sp. groupings & Island & Habitat & No. individuals \\
\hline \multicolumn{4}{|l|}{ Subgenus Hegeter s. str. } \\
\hline \multicolumn{4}{|l|}{ tristis group } \\
\hline H. tristis $\dagger$ & $\mathrm{F}, \mathrm{L}, \mathrm{T}, \mathrm{H}, \mathrm{LP}$ & $\mathrm{a}, \mathrm{b}$ & $2(\mathrm{~A}, \mathrm{H})$ \\
\hline H. grancanariensis & $\mathrm{C}$ & $a, b$ & 1 \\
\hline \multicolumn{4}{|l|}{ H. webbianus } \\
\hline amaroides group & $\mathrm{C}$ & $\mathrm{b}, \mathrm{c}$ & 1 \\
\hline H. amaroides & $\mathrm{T}, \mathrm{G}, \mathrm{H}$ & $\mathrm{b}, \mathrm{c}, \mathrm{d}, \mathrm{e}$ & $3(\mathrm{~T}, \mathrm{G}, \mathrm{H})$ \\
\hline \multicolumn{4}{|l|}{ H. glaber } \\
\hline brevicollis group & LP & $b, c, d$ & 1 \\
\hline H. brevicollis & $\mathrm{T}$ & $\mathrm{b}$ & 2 \\
\hline H. brevicornis $\ddagger$ & G & b & \\
\hline H. gomerensis & G & $\mathrm{b}, \mathrm{c}, \mathrm{e}$ & 1 \\
\hline H. proximus $\ddagger$ & $\mathrm{T}$ & $\mathrm{b}$ & \\
\hline H. excisus & $\mathrm{T}$ & $\mathrm{b}, \mathrm{e}, \mathrm{d}$ & \\
\hline H. transversus & $\mathrm{T}$ & $\mathrm{d}, \mathrm{e}$ & 1 \\
\hline H. tenuipunctatus & $\mathrm{T}$ & $\mathrm{f}$ & 1 \\
\hline H. lateralis & $\mathbf{T}$ & $\mathrm{f}$ & 1 \\
\hline \multicolumn{4}{|l|}{ H. intercedens } \\
\hline impressus group & $\mathrm{T}$ & $a, b$ & 1 \\
\hline H. costipennis & $\mathrm{C}$ & $b, c$ & 1 \\
\hline H. impressus & $\mathrm{C}$ & $\mathrm{b}$ & 1 \\
\hline \multicolumn{4}{|l|}{ H. subrondatus } \\
\hline abbreviatus group & $\mathrm{C}$ & $\mathrm{a}$ & 1 \\
\hline H. abbreviatus & $\mathrm{C}$ & $\mathrm{e}$ & \\
\hline H. latebricola $\ddagger$ & $\mathrm{S}$ & - & \\
\hline \multicolumn{4}{|l|}{ Subgenus Pseudotalpophila } \\
\hline H. plicifrons & $\mathrm{F}$ & $\mathrm{b}$ & 1 \\
\hline H. fernandezi & $\mathrm{F}$ & $\mathrm{c}$ & 1 \\
\hline \multicolumn{4}{|l|}{ Subgenus Homalapipleurus } \\
\hline H. politus & $F, L, A$ & $\mathrm{~b}$ & $5(\mathrm{~F}, \mathrm{~L}, \mathrm{~A})$ \\
\hline H. gonzalezi $\ddagger$ & $\mathrm{F}$ & $\mathrm{a}$ & \\
\hline
\end{tabular}

th. tristis is found in other East African (Macaronesian) archipelagos.

$\$$ Not included in the present study.

Abbreviations for the islands are as follows: A, Alegranza; C, Gran Canaria; F, Fuerteventura; G, Gomera; H, Hierro; T, Tenerife; LP, La Palma; S, Salvagem Islands. Abbreviations for habitats are: a, coastal dunes; b, xerophilous low or medium altitude; c, mountainous, deforested areas; d, mountainous, pine forest; e, humid forest; $f$, mountainous, high altitude.

1 (255 bp long including primers) were $5^{\prime}$-CCTACAGGAATTAAAGTTTTTAGATGATTAGC-3' and 5'-ATAGGGGGAATCAGTGAACTAGTCC$3^{\prime}$, their $5^{\prime}$ end positions corresponding to sites 2410 and 2665 of the Drosophila yakuba mitochondrial genome. Fragment 2 ( $311 \mathrm{bp}$ long) corresponds to the $3^{\prime}$ end of the COI gene. The oligonucleotides used in this case were 5'-GTAAACCTAACATTTTTTCCTCAACA- $3^{\prime}$ and 5'-TCCAATGCACTAATCTGCCATATTA-3' (primers UEA9 and UEA10 of Lunt et al., 1996), with positions for the $5^{\prime}$ ends in the D. yakuba mitochondrial genome of 2727 and 3038, respectively. Each PCR cycle comprised denaturation at $94^{\circ} \mathrm{C}$ for $30 \mathrm{~s}$, annealing at $50^{\circ} \mathrm{C}$ for $1 \mathrm{~min}$, and primer extension at $72^{\circ} \mathrm{C}$ for 1 min. Purified single-stranded DNA was prepared by using one of the two primers biotinilated at its $5^{\prime}$ end in the PCR reaction. The two DNA strands were separated with magnetic beads coated with streptoavidin (DYNAL) according to the manufacturer's recommendations. The sequences were generated using the dideoxy Sanger method with fluoresceinated sequencing primers and a Pharmacia ALF automatic sequencer. Most of the individuals were sequenced more than once from independent PCR amplifications. Sequence data were analysed by 
multialignment with the Lasergene program MegAlign (DNAstar, 1992).

\section{Phylogenetic analyses}

Maximum Parsimony analysis of the sequence data was performed using the PAUP computer software package (Swofford, 1993). Because of the number of taxa involved in the analyses we performed heuristic bootstrap searches with random addition of taxa with 10 repetitions for each of 100 replications. Substitution and character weighting were tried in PAUP, creating step matrices that give particular 'cost' values to transversions with respect to transitions and giving less weight to third codon positions with respect to first and second ones. The MACCLADE program (Maddisson \& Maddison, 1992) was used to test the number of extra steps required for alternative topologies to the most parsimonious tree (MPT). The 'Stasis and Changes' option in the Chart menu was used to estimate the number of transitional and transversional changes deduced from trees.

Total substitution rates were calculated using the Kimura 2-parameter model (Kimura, 1980). Phenograms based on sequence distances were constructed using the Neighbour-Joining (NJ) (Saitou \& Nei, 1987) procedure with the Phylogeny Inference Package (PHYLIP) (Felsenstein, 1993). Bootstrap values were based on 500 replications. Nonsynonymous substitution rates were estimated by the method of Li et al. (1985), with the modifications proposed by Li (1993). Relative rate tests (Sarich \& Wilson, 1967) were performed according to the method of Wu \& Li (1985).

\section{Results}

\section{Sequence variation}

A total of 438 nucleotide positions of the COI gene have been examined in 22 sequences from 17 Canarian Hegeter species as well as two outgroup species (Fig. 2). Of these, 166 were polymorphic, giving a total of 130 phylogenetically informative characters. Among the Canarian sequences 139 positions varied, 21 of them at first codon positions whereas all the remaining changes were at third codon positions. The transition/transversion ratio estimated from the MPT obtained was 2.8 , with most changes (35 per cent) being from $T$ to $C$. The sequences have an average frequency of $\mathrm{A}+\mathrm{T}$ nucleotides of 65 per cent across all taxa, increasing to about 80 per cent at third codon positions. In a previous study including 365 bp of COI from Canarian Pimelia, a genus belonging to the same beetle subfamily, similar frequencies of $\mathrm{A}+\mathrm{T}$, transition/transversion ratios, types and frequencies of substitutions were found (Juan et al., 1995). When comparing the two data sets, which are coincident for approximately $200 \mathrm{bp}$, it appears that 64 per cent of the total polymorphic sites vary in both Hegeter and Pimelia at exactly the same positions (75 per cent of these are at third codon positions and 40 per cent involve $\mathrm{T} \leftrightarrow \mathrm{C}$ transitions only in both genera).

Comparison of the inferred amino acid sequences of COI obtained in Hegeter showed that fragment 1 is invariant among the Canarian sequences, which shared seven amino acid differences with respect to the outgroups. Fragment 2 is more variable at the amino acid level; there are 19 variable amino acid positions, four of them showing amino acid differences among the Canarian Hegeter. All but three of the amino acid substitutions are conservative. In amino acid position number 47 (nucleotide positions 139-141) all species endemic to Gran Canaria (except $H$. webbianus) plus $H$. politus from Fuerteventura have serine, while the remaining Canarian species have alanine. At amino acid position 67 (nucleotide positions 199-201) all Tenerifean endemic species except $H$. intercedens have threonine, whereas the other groups have serine or isoleucine ( $H$. glaber, La Palma). Therefore, two island groups of species (Gran Canaria and Tenerife) are defined by particular amino acid replacements.

\section{Intraspecific variation}

Four species were sequenced for more than one individual. Hegeter politus sequences were obtained from three individuals from the same population of Fuerteventura plus one each from Lanzarote and the islet of Alegranza. Hegeter amaroides sequences came from three individuals collected in Tenerife, Gomera and Hierro, respectively. Hegeter tristis was sequenced in Hierro and Alegranza individuals and $H$. brevicollis (Tenerife) in two individuals from the same population. The intraspecific variation was 0.8-1.5 per cent for species that occur in a single island (not shown) and 7-9.5 per cent for individuals of the same species but from different islands. In all cases in which more than one individual was sequenced for a given species, the haplotypes from those individuals formed a monophyletic group.

\section{Phylogenetic analysis}

An heuristic search using PAUP and assuming an 
equal weight for all characters produced two MPTs equal in length (580 steps, consistency index $=0.44$, retention index $=0.49$ ). The topology of the bootstrap tree supported monophyly for the Fuerteventura/Lanzarote species group which occupies an ancestral position in the tree, with all the other clades, namely Gran Canarian, Tenerifean and western islands species groups, being derived from one another in a monotonic way (Fig. 3a). However, bootstrap values were low (less than 50 per cent) for most of the basal nodes and some of the alternative topologies were only a few steps apart. The tree also suggests a polyphyletic origin of the Gran Canarian group of species and relates $H$. webbianus to the Tenerifean lineage. Fitch \& Ye (1991) have argued that weighted parsimony is more likely to infer the correct or a better tree than equally weighting all characters and state changes. Weighting reduces the level of noise in a data set by giving emphasis to the rare events, which in coding sequences are generally transversions and substitutions at first and second codon positions. Thus, for substitution weighting the transition/transversion ratio estimated from the MPT was used, giving a weight of 3:1 of transversions vs. transitions. Similar native transversion/transition ratios for COI have been estimated in other coleopterans (Funk et al., 1995). Also, the more variable third codon positions were given less weight than the conserved first and second positions.

The most consistent trees were obtained when

FRAGMENT 1

subrondatus amaroides (G) amaroides $(\mathrm{H})$ amaroides (T) brevicollis costipennis fernandezi

glaber gomerensis grancan. impressus intercedens lateralis politus (A) politus (F) politus (L) plicifrons tenuipun. transversus tristis (A) tristis (H) webbianus Tentyria Pimelia

subrondatus amaroides (G) amaroides (H) amaroides $(T)$ brevicollis costipennis fernandezi glaber gomerensis grancan. impressus intercedens lateralis politus ( $A$ ) politus (F) polits (L) plicifrons tenuipun. transversus tristis (A) tristis (H) webbianus Tentyria pimelia

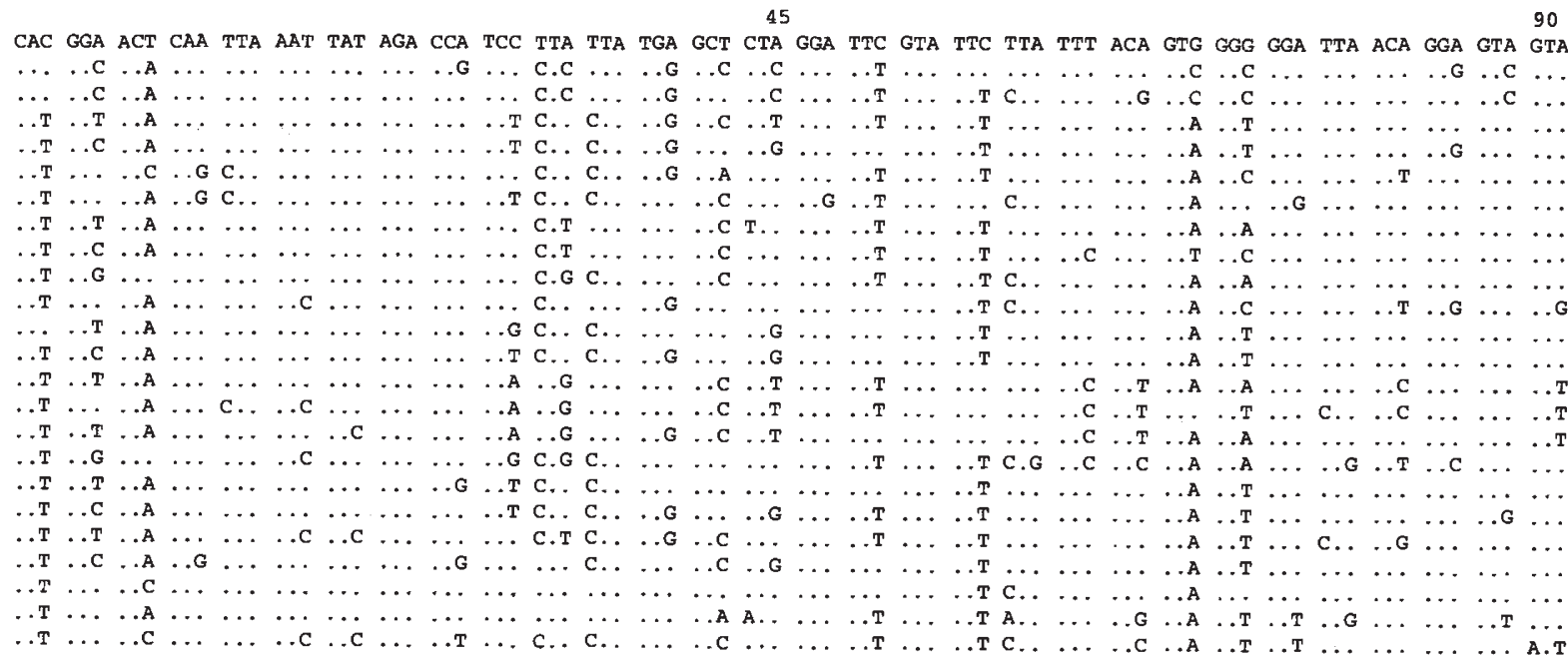

135 180

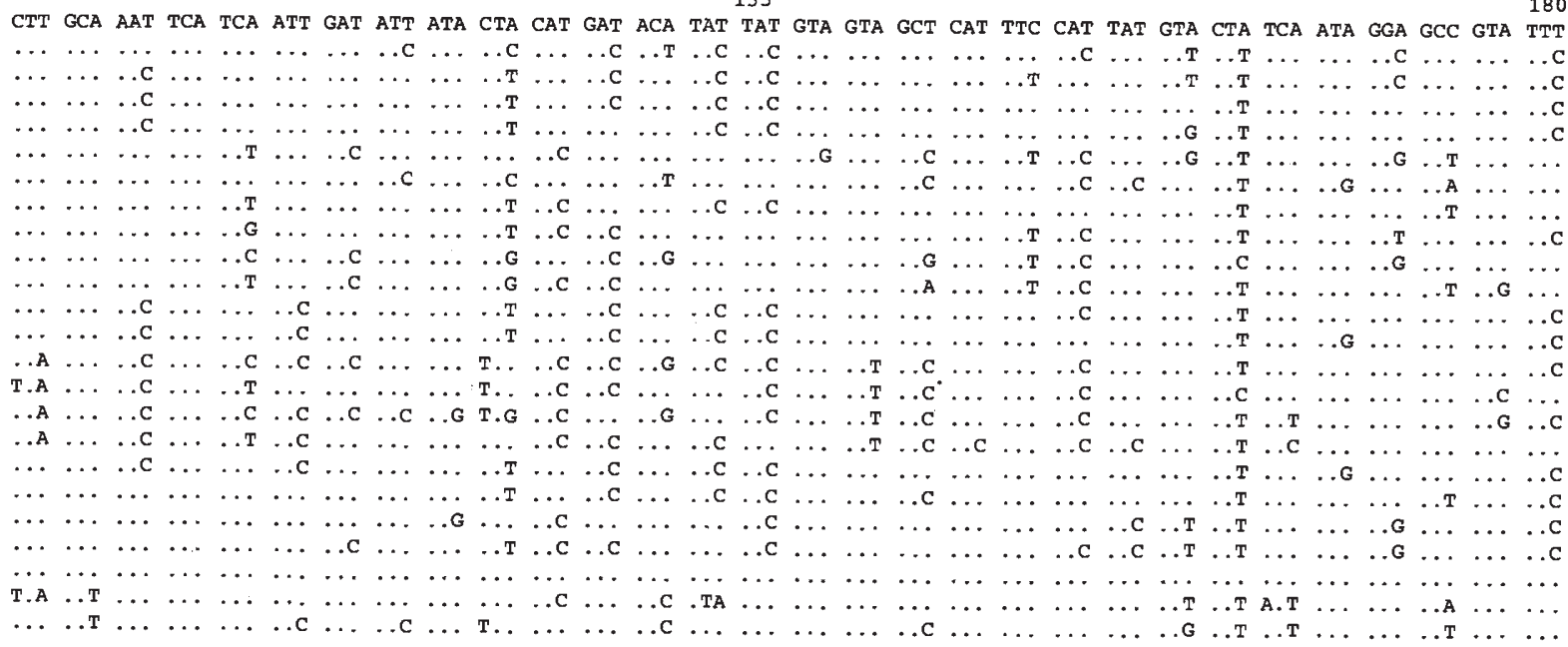

Fig. 2 Sequence alignment of COI DNA sequences in species of Hegeter plus two outgroup species used for comparison (Tentyria and Pimelia). Identity to the sequence of $H$. subrondatus is indicated by a dot. For intraspecific variation, only the sequences of species from different islands are shown. Abbreviations for the islands are as in Table 1. 


subrondatus
amaroides (G)
amaroides (H)
amaroides (T)
brevtcollis
costipennis
fernandezi
glaber
gomerensis
grancan.
impressus
intercedens
lateralis
politus (A)
politus (F)
politus (L)
plicifrons
tenuipun.
transversus
tristis (A)
tristis (H)
webbianus
Tentyria
Pimelia

subrondatus amaroides (H) amaroides $(T)$ brevicollis costipennis fernandezi glaber gomerensis grancan. impressus inpressus lateralis politus (A) politus (F) politus L) tenuipun. transvesus tristis (H) webbianus Tentyria Pimelia amaroides (G) plicifrons tristis (A)

\section{FRAGMENT 2}

195 GCA ATT TTC GGA GGA $45 C$ TAC CCT GAT GCC TAT ACT ata tGa Aat atT ATt TCT TCA ATt

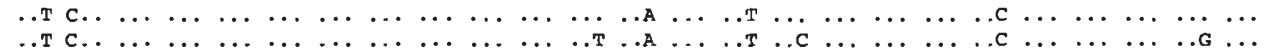

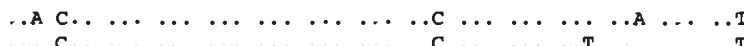

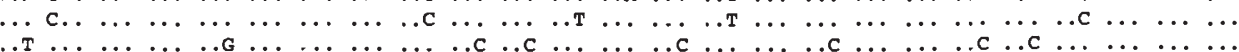

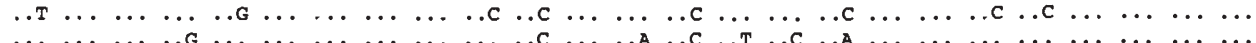

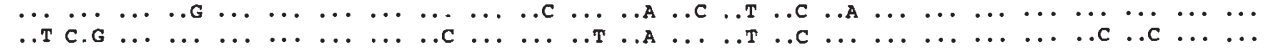

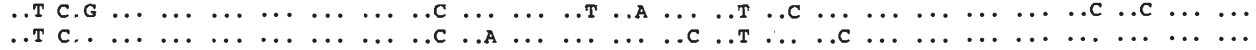

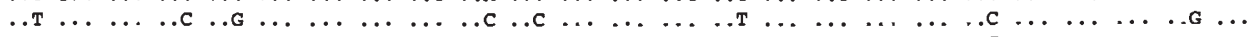

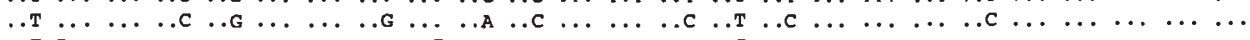

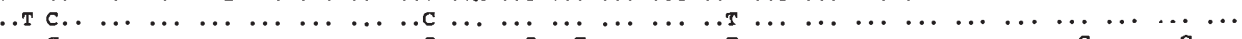

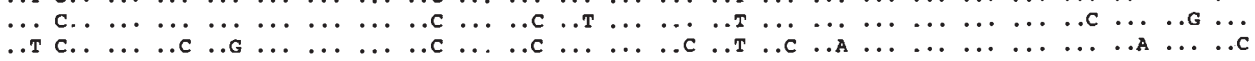

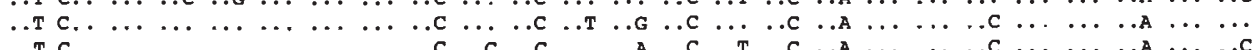

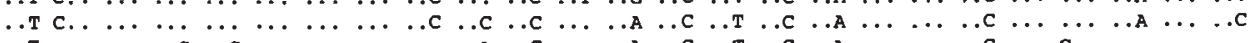

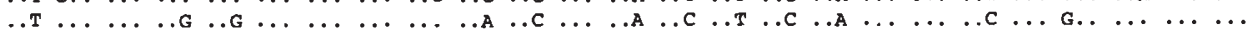

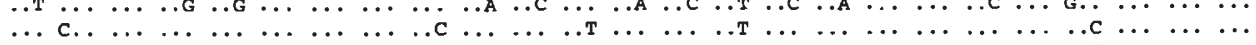

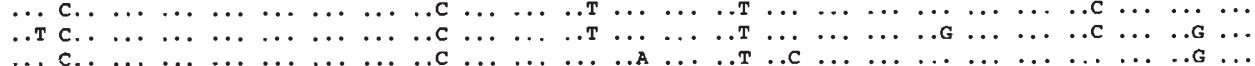

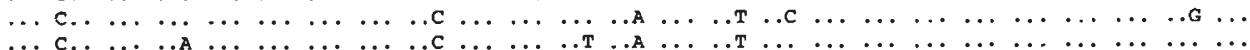
$\begin{array}{llllllllllll}\ldots & \ldots\end{array}$

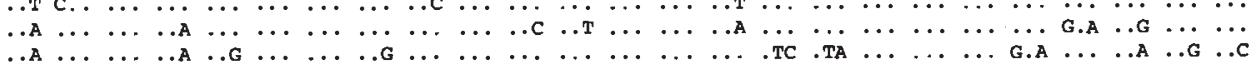

90

135

GGA TCA ATT ATT TCC TTA ATT GGG GTT CTA TAT TTA ATT TTT ATT ATT TGA GAA AGA TTT TCA TCC TCT CGA AAG ACT ATT TTC CCA TTA

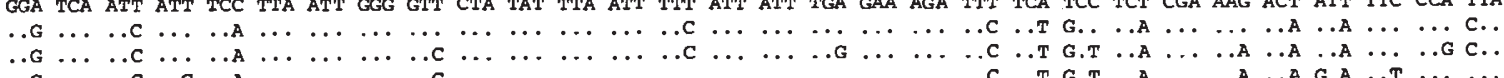

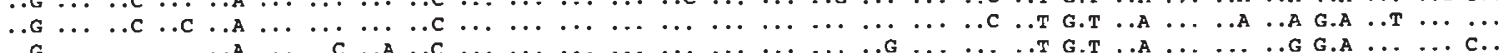

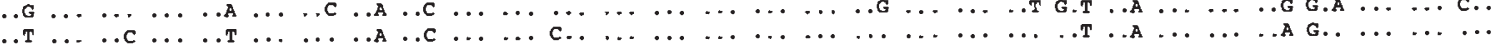

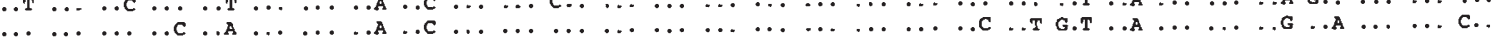

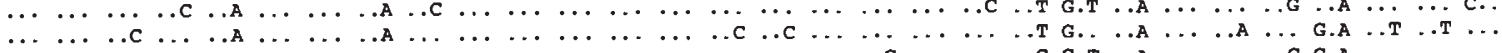

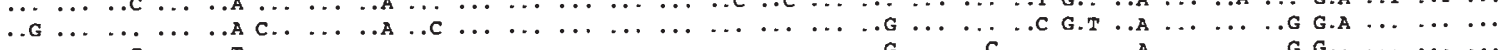

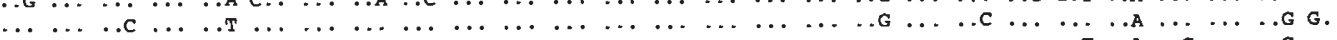
$\begin{array}{ll}\ldots & \ldots\end{array} \ldots$

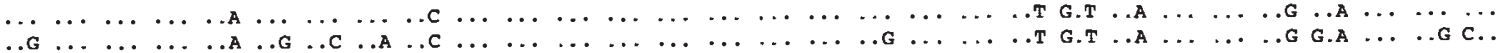

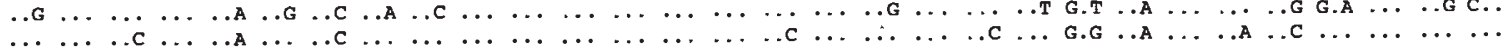

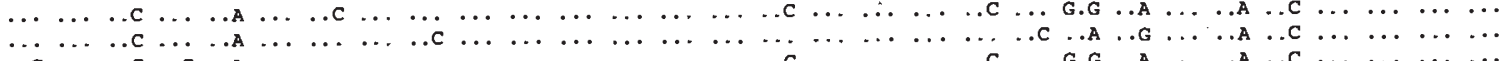

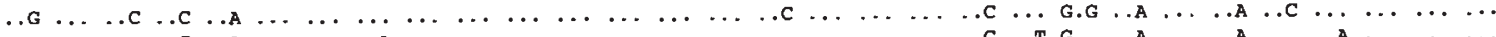

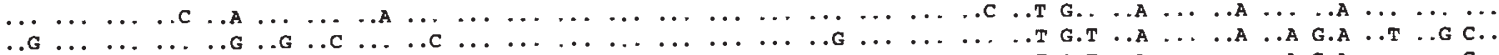

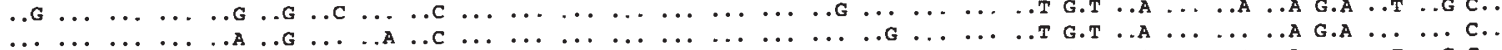

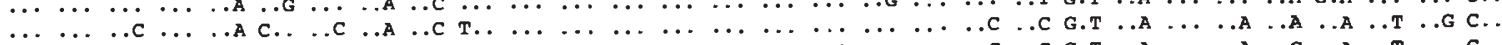

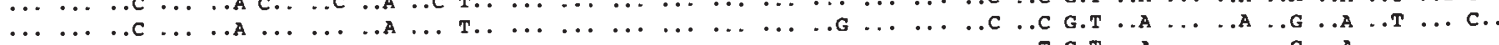

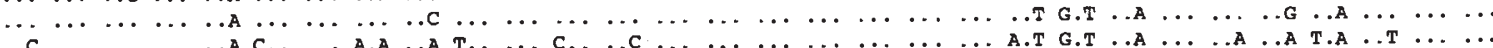

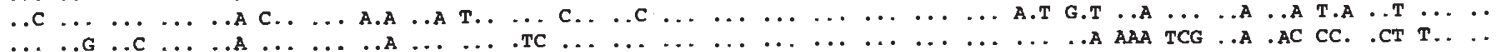

180 225

subrondatus AAC ATA ACA TCG TCA ATT GAA TGA TTA CAA TCA TCA CCC CCA GCA GAA CAT AGA TAT TCT GAA CTT CCA ATA TTA ACA

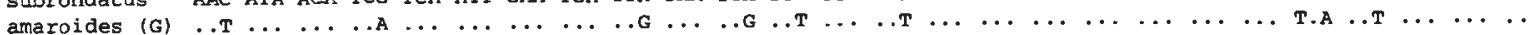

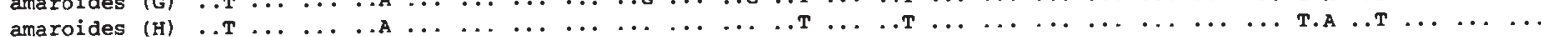

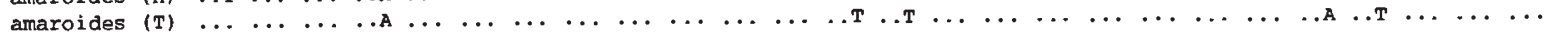
brevicollis costipennis fernandezi glaber gomerensis grancan. impressus intercedens lateralis politus (A) politus (F) politus (L) plicferons tenuipun. transversus tristis (A) tristis (H) webbi anus Tentyria Pimelia

Fig. 2 continued. 

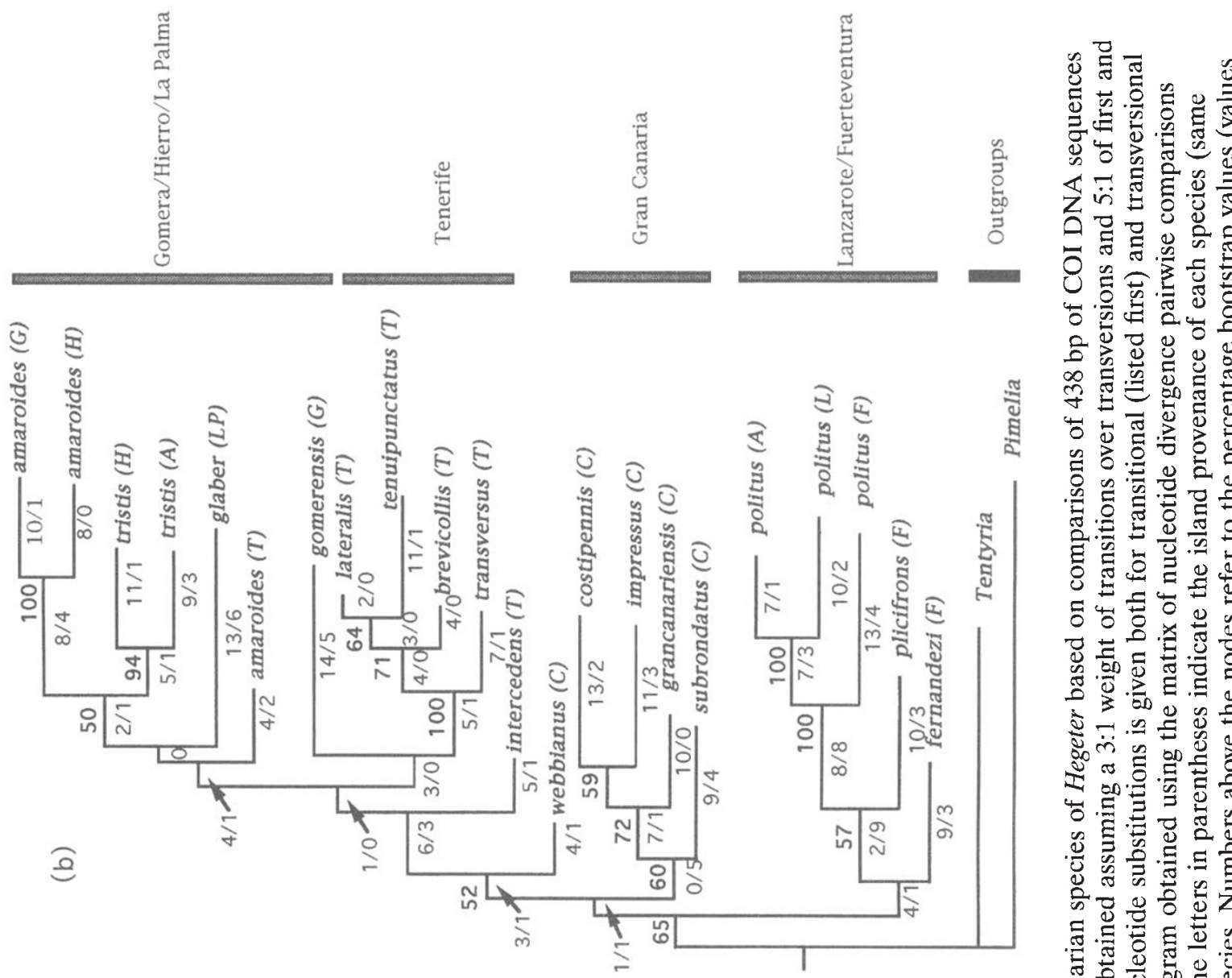

ठํ.

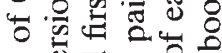

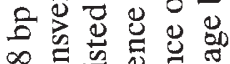

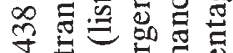

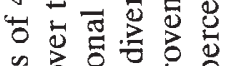

光。일

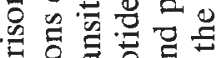

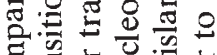

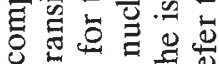

5

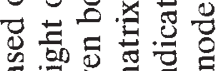

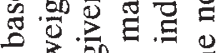

$\circ$ on

ङें

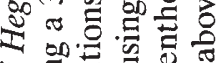

पे

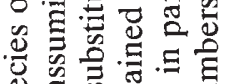

ब क ज

के 웡혀

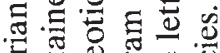

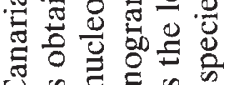

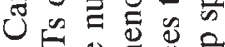

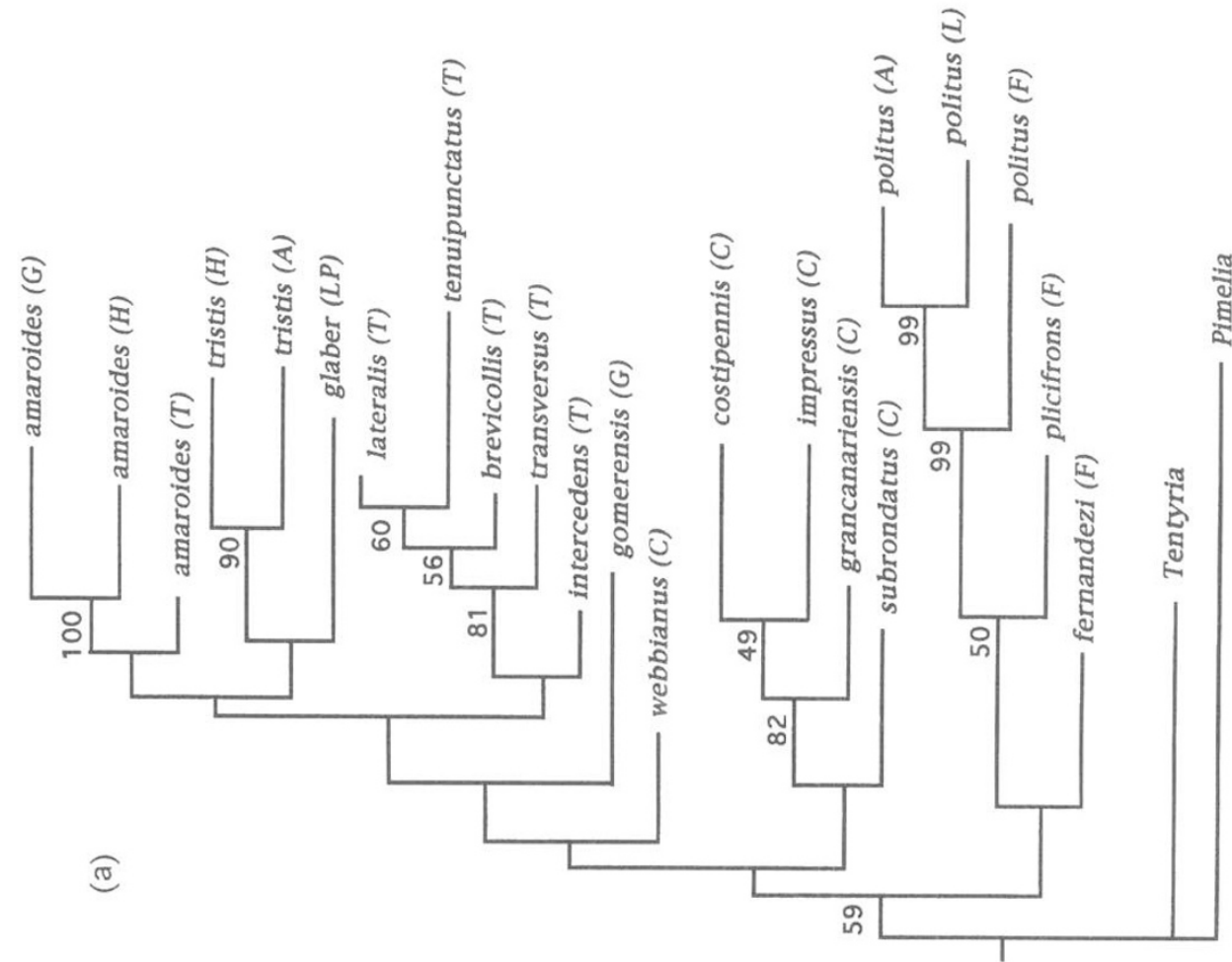

.

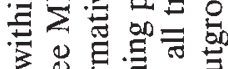

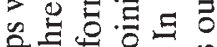

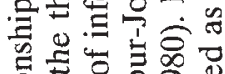

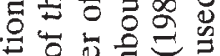

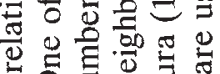

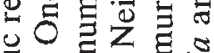

包包选

焉的出

월

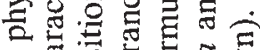

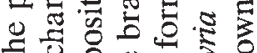

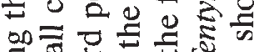

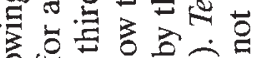

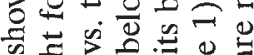

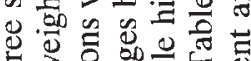

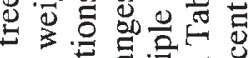

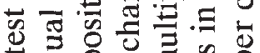

항음

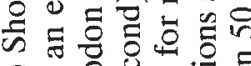

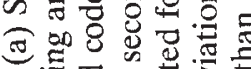

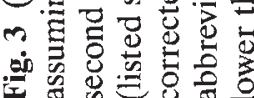

(c) The Genetical Society of Great Britain, Heredity, 76, 392-403. 
Fig. 3 continued.

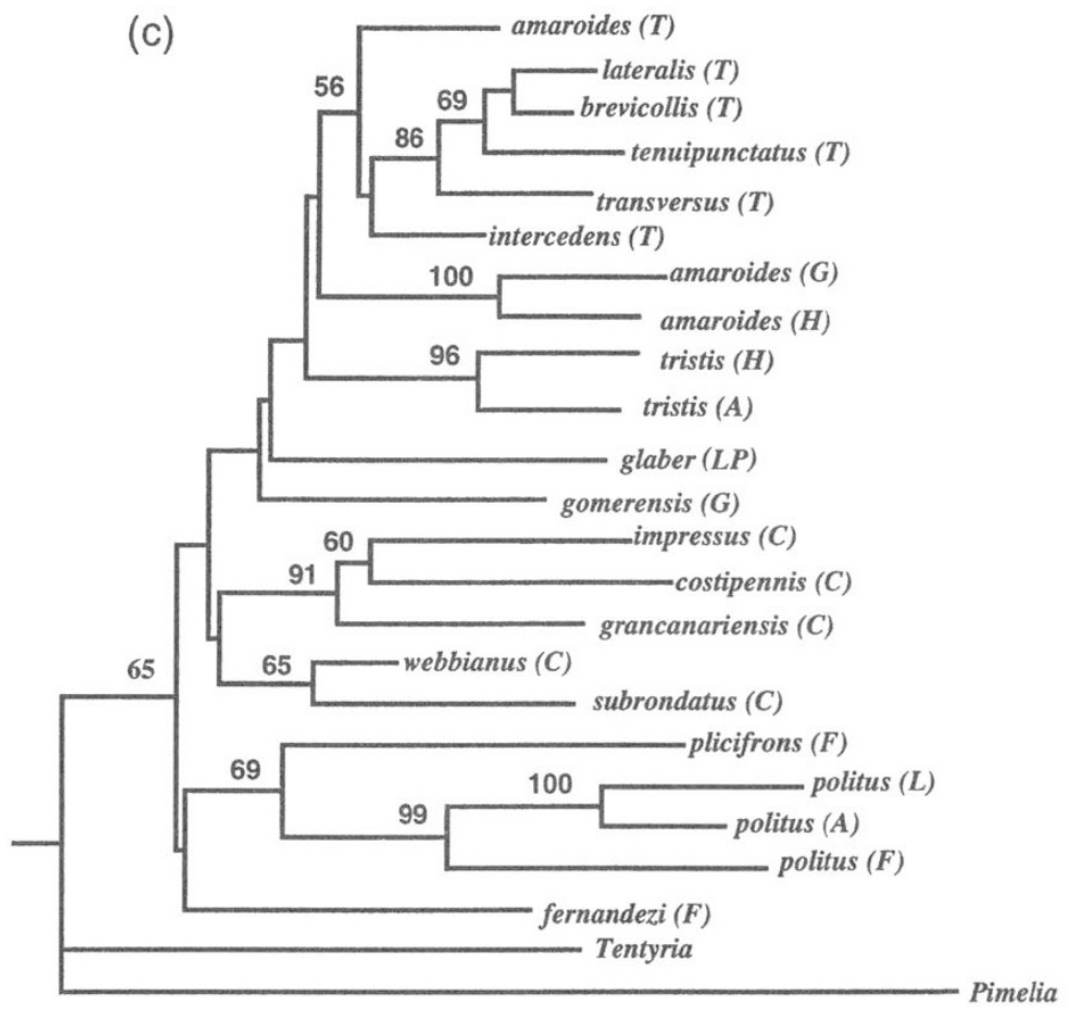

combining both weighting methodologies (weights of 3:1 transversion vs. transition; 5:1 first and second codon positions vs. third codon positions). The bootstrap shortest tree obtained in this search is presented in Fig. 3b. This tree topology is similar to the equally weighted tree. The main groups are supported by relatively few nucleotide substitutions (2-5) and moderate bootstrap values (Fig. 3b). It has been suggested that increasing the weight given to transversions results in better resolved trees but completely ignoring transitions can give less resolution (Funk et al., 1995). In our case, the topology of the five MPTs obtained when only considering transversions was remarkably similar to the previous ones but differed by forcing $H$. webbianus into the Gran Canarian species group, making it monophyletic. The program MACCLADE was used to look for alternative topologies, changing the relative positions of the main clades. Swapping the Fuerteventura/ Lanzarote and Gran Canarian lineages implied two extra steps in the length of the tree. All other changes in the relationships between groups increased significantly the number of nucleotide substitutions necessary to support alternative topologies. Finally, considering nonsynonymous substitutions exclusively gave a poor phylogenetic resolution because of the low number of informative characters in the data set.

Overall, we favour the topology shown in Fig. 3b, which relates the Fuerteventura group to the Gran Canarian one; this then joins to the Tenerife + western islands species group. In the latter group, the within lineages relationships are difficult to establish unambiguously because they are less stable when trying different weighting strategies. Nevertheless, a subgroup consisting of closely related Tenerifean species is supported by six substitutions and a bootstrap value of 100 per cent, and a group formed by $H$. amaroides (Tenerife, Gomera and Hierro), $H$. tristis (Hierro and Alegranza) and H. glaber (La Palma) is supported by five nucleotide substitutions.

A phenetic analysis with the NJ method using the distance matrix calculated by the 2-parameter formula of Kimura (the matrix is available from the authors on request) was performed. The maximum and minimum evolutionary distances between species are 20.13 per cent between $H$. politus (Lanzarote) and $H$. costipennis (Gran Canaria) and 3.26 per cent between $H$. lateralis and $H$. tenuipunctatus (Tenerife), respectively. The topology of the NJ tree obtained (Fig. 3c) is similar to the one obtained by the parsimony analysis, resulting in the 


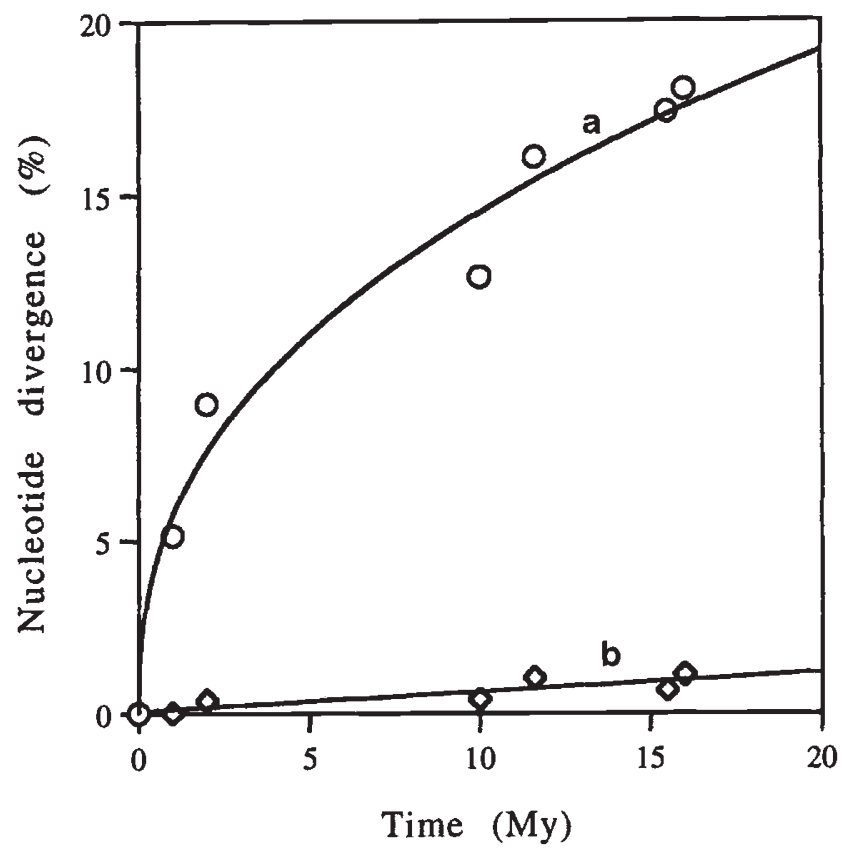

Fig. 4 Relationship between time of divergence estimated by the maximum geological age of individual Canary islands (values in Fig. 1) and maximum sequence divergence comparisons between taxa in different islands. The sequence divergence used between Tenerife and La Palma is the estimate obtained comparing the morphologically related Hegeter amaroides (Tenerife) and $H$. glaber $(\mathrm{La}$ Palma). The sequence divergence between the two forms of $H$. amaroides in Gomera and La Palma was used for the comparison between these islands. (a) Curve obtained considering the total sequence distances; (b) curve considering the nonsynonymous distances.

same relative positions of the main groups but different in the position of $H$. webbianus, here placed in the Gran Canarian group. The internode lengths separating the island groups are very short, indicating a rapid speciation and radiation of the species in the Canaries, and therefore making it difficult to achieve enough resolution to establish the between island group relationships consistently. Relative rate tests were performed for 10 comparisons between taxa which occur in the same or different islands. The results showed no evidence of rate heterogeneity either at 4-fold or 2-fold degenerate positions (not shown), and therefore a relatively steady molecular clock can be assumed. Figure 4 shows a plot of the maximum evolutionary distances between taxa on different islands based on all (A in Fig. 4) or only nonsynonymous (B in Fig. 4) sites with respect to the maximum estimate of age for the younger island in each comparison.

\section{Discussion}

\section{Sequence variation}

The estimates for sequence variation, average nucleotide composition, transition/transversion ratios and frequency of each nucleotide change are remarkably similar in the COI DNA sequences of the Canarian Hegeter (this paper) and Pimelia (Juan et al., 1995). Furthermore, the transition bias described in the mitochondrial DNA of other insects (DeSalle et al., 1987; Tamura, 1992; Brown et al., 1994; Funk et al., 1995) is clearly present in these Canarian tenebrionids. Also, a comparison of the same nucleotide positions sequenced in the two beetle data sets shows that a majority of substitutions are occurring at the same sites and are of the same type. This strongly suggests that the molecular mechanisms driving the evolution of these mitochondrial sequences are very similar in the two genera and encourages the comparison of the inferences made from the sequence variation of the two data sets.

The COI protein, which is involved in the mitochondrial respiratory chain, has been divided into 25 structural regions falling into five different categories (Saraste, 1990; Lunt et al., 1996). The sequence variability found among the Hegeter species is maximum in the last 120 nucleotides of fragment 2, which is coincident with the $3^{\prime}$ end of the gene. High variability of the $3^{\prime}$ end of both subunits of $\mathrm{CO}$ (COI and COII) has been previously reported at deep phylogenetic levels (different orders of insects) (Liu \& Bechenbach, 1992; Lunt et al., 1996). The present results show that variability is also present, at least for COI, at the level of closely related species.

\section{Phylogenetic inferences}

Parsimony analysis supports monophyly for the three island variants of $H$. politus (bootstrap value 100 per cent). The evolutionary distances between the sequences of individuals of $H$. politus from different islands are high (5.43-11.58 per cent), indicating that this species has been diverging anagenically for a long period of time in the eastern islands. It suggests an origin for the species in Fuerteventura, which is the oldest island in the archipelago (20 My).

The group of species occurring in the eastern Canary islands, $H$. politus, $H$. plicifrons and $H$. fernandezi (the Fuerteventura group), is a monophyletic clade for the plicifrons-politus taxa, but the 
position of fernandezi is not well resolved. Hegeter fernandezi contains the most diverged Hegeter COI sequence in the Canaries, which perhaps is related to the ancestral colonizer of Fuerteventura. Interestingly, this species occurs in a very restricted area on the top of the mountains of the Jandía peninsula (Fuerteventura). Hegeter politus is remarkable in having a stridulatory plectrum on the posterior femurs which is absent from all the other Hegeter taxa (Español, 1957a,b). Hegeter politus and H. plicifrons are probably the result of radiation of an extinct species on the eastern islands, which also colonized Gran Canaria. This explanation is also supported by the fact that the same inferred amino acid replacement at amino acid position 47 (fragment 2), which defines the Gran Canarian group, is present in the sequence of $H$. politus (Fuerteventura).

Those species occurring in Gran Canaria, namely the Gran Canarian group, $H$. subrondatus, $H$. grancanariensis, $H$. impressus and $H$. costipennis, are probably a monophyletic group (60 per cent bootstrap value in the parsimony analysis), although the NJ tree relates $H$. subrondatus to $H$. webbianus in 65 per cent of the bootstrap replications. Hegeter webbianus itself seems to be the result of a different, older colonization event, and maybe a member of its radiation colonized Tenerife. This molecular phylogeny disagrees with the opinion of taxonomists (Español, 1957a,b) who considered $H$. webbianus closely related to $H$. grancanariensis and $H$. tristis, possibly even a single species. The phylogenetic position of $H$. amaroides from Tenerife is not clear as different results have been obtained by parsimony and distance methods, and the parsimony trees themselves differ in the position of this taxon. Hegeter amaroides from Gomera and Hierro are, however, a monophyletic grouping (bootstrap value of 100 per cent).

The relationships of the five exclusive endemic species of Tenerife with the Gomera species $H$. gomerensis and $H$. glaber from La Palma are more obscure. Within Tenerife, $H$. lateralis, $H$. tenuipunctatus, $H$. brevicollis and $H$. transversus form a closely related monophyletic group, the result of a relatively recent radiation to which $H$. gomerensis seems to be related. This supports the distinctness of the latter species, considered a mere variety by Wollaston (1864) and Español (1957a). All exclusive Tenerifean species but one show the same specific amino acid replacement at position 67 (fragment 2) which defines the group in the same manner as described above for the Gran Canarian clade. Finally, $H$. glaber from La Palma is related to the hetero- geneous group of taxa which occur in several islands (H. tristis and $H$. amaroides).

The phylogenetic relationships among the main species groups contain many uncertainties, as shown by the weak bootstrap values obtained, which in many cases coincide with very short internode lengths in the distance tree. This is partly caused by the high proportion of transitional substitutions, which give information about recent divergences but introduce significant levels of noise for inferring ancient relationships (Funk et al., 1995). It seems unlikely that the number of characters used in the analysis is insufficient to establish the relationships among groups, because a similar study with a shorter DNA sequence $(365 \mathrm{bp})$ of the same COI gene was able to resolve the interisland group relationships in the genus Pimelia (Juan et al., 1995). Short internode lengths have been explained as the result of a rapid origin and radiation of lineages (Kraus \& Miyamoto, 1991; Barrio et al., 1994; Emerson \& Wallis, 1995). Pamilo \& Nei (1988) have argued that a tree constructed from DNA sequences of a single gene can differ considerably from the species tree if the time of divergence between species is short. This makes it difficult to reach the resolution required to clarify the phylogenetic relationships between groups in fast cladogenetic lineages, even when large DNA sequences are used in the analysis.

If we assume such an evolutionary scenario of rapid radiation for the Hegeter taxa, it would imply that individual Canary islands were colonized soon after they emerged by migrants from a close existing island, followed by within-island radiations and speciation events. In the case of the more habitatdiverse Gran Canaria and Tenerife islands, this would have probably occurred relatively quickly according to this explanation. The COI phylogenies obtained for the Canarian Pimelia differ with respect to the Hegeter ones in having a better resolution of the different clades, as shown by the higher statistical support of the main island species groups (Juan et al., 1995). Hegeter seems to be a better colonizer than Pimelia of empty habitats, including lava flows of historical age with very little vegetation, and is also found on the Lanzarote islets (Alegranza and Montaña Clara) from which Pimelia is absent. This could be because of different life history characteristics and/or reproductive strategies in the two genera, and may account for the observed differences in their mitochondrial phylogenies.

Despite the uncertainties detailed above and the limitations of using few individuals per taxon, all parsimony and distance solutions suggest a colonization in the direction Fuerteventura $\rightarrow$ Gran Canar- 
ia $\rightarrow$ Tenerife $\rightarrow$ Gomera. These sequential colonizations are the most plausible explanation when we consider both the timing of the islands' formation and their geographical distribution in the archipelago (see Fig. 1). Assuming that a molecular clock exists and exhibits the generally accepted rate of substitution of 2 per cent/My for mtDNA (DeSalle et al., 1987), we can estimate the colonization times from the maximum evolutionary distances between species on different islands. Lanzarote and Gran Canaria would have been colonized by Fuerteventuran ancestors at a maximum of 8.5-9 My, Tenerife at about $8 \mathrm{My}$ and Gomera 6.3 My. These estimates are in all cases lower than the accepted physical datings for these islands. They also imply only a small time difference between the colonizations of Gran Canaria and Tenerife (see above). In the genus Pimelia (Juan et al., 1995) a similar colonization pattern was deduced, except that Tenerife seems to have been colonized before Gran Canaria by ancestors in Fuerteventura (at an estimated $8 \mathrm{My}$ $\mathrm{BP}$ ), and was the source of colonizers for Gran Canaria and Gomera at maximum estimated times of 7.5 and $5.5 \mathrm{My}$, respectively.

The evolutionary distances between the closely related Tenerifean species indicate that their radiation is quite recent (1-3 My). The mountainous species $H$. lateralis and $H$. tenuipunctatus probably appeared from coastal ancestors after the last series of volcanic eruptions which formed the Las Canadas volcanic edifice, beginning around 2 My ago (Ancochea et al., 1990).

On the other hand, the colonizations of the younger islands of Hierro and La Palma, and the relationship of $H$. gomerensis to the extant Tenerifean species are not so clear. All the estimates obtained for time of divergence seem to be higher than the age of the islands, which are the youngest (1-2 My) in the archipelago. This could result from acceleration of the sequence divergence caused by founder effects, but the relative rate test provides no evidence of this. Another possibility is that COI sequences have a faster rate of substitution than 2 per cent/My. This may be so, but to explain some levels of sequence divergence it would have to be in the order of 5 per cent/My. An example of this is $H$. glaber (La Palma) and $H$. amaroides (Tenerife) with 9 per cent divergence, with La Palma being only 2 My old. Español (1957a,b) considered H. glaber to be morphologically very close to $H$. amaroides. It seems unlikely that the COI region will have accelerated in certain cases (see relative rate test), and a more likely explanation is that the glaber and amaroides lineages diverged on Tenerife and that of glaber colonized La Palma during the last 2 My. If this is so, then maybe a glaber-like lineage sequence stills exists on Tenerife: further work can explore this possibility.

The distribution of $H$. tristis has been suggested to be the result of human transportation (Español, 1957a,b; Oromí, 1982a,b). The species is clearly anthropophilous, and has a widespread distribution in all Macaronesian islands and in some parts of the Saharan coast. We have so far examined the $H$. tristis DNA sequences from two islands only (Alegranza, c. $15 \mathrm{My}$ and Hierro, $1 \mathrm{My}$ and they are monophyletic with a bootstrap value of 94 per cent). No definitive proof or refutation of supposed human transportation can be given yet, and the evolutionary distances and time of divergence estimates obtained for this species have to be regarded with some caution. But its phylogenetic position from our COI data suggests that it has arisen relatively recently on the western islands of the Canaries.

The overall picture of colonization of the Canaries by this tenebrionid beetle Hegeter, revealed from its mtDNA phylogeny, is of sequential island invasion with more rapid establishment and radiation than its more ponderous cousin Pimelia. It will be interesting and informative to compare this picture with data we will obtain from nuclear sequence analysis.

\section{Acknowledgements}

We thank Barry Richardson, Brent Emerson and Kamal Ibrahim for discussions and help with computer data analysis. Ken Wolfe provided the Li93 program, modified by adding an insect mitochondrial genetic code option, Joan Pons collected specimens of Tentyria and Diane Alden helped with figures. C. J. was supported by an European Union fellowship. The work has been financed by an EU Biotech grant (G.M.H.) and Spanish DGCYT PB 93-0419 (P.O.).

\section{References}

ANCOChEA, E., FUSTER, J. M., IBARrola, E. ET AL., 1990. Volcanic evolution of the island of Tenerife (Canary Islands) in the light of new K-Ar data. J. Volcanol. Geotherm. Res., 44, 231-249.

ANGUITA, F. AND HERNAN, F. 1975. A propagating fracture model versus a hot spot origin for the Canary Islands. Earth Planet. Sci. Lett., 27, 11-19.

BARRIO, E., LATORRE, A. AND MOYA., A. 1994. Phylogeny of the Drosophila obscura species group deduced from mitochondrial DNA sequences. J. Mol. Evol., 39, $478-488$.

BROWN, J. M., PELLMYR, O., THOMPSON, J. N. AND HARRISON, 
R. G. 1994. Phylogeny of Greya (Lepidoptera: Prodoxidae), based on nucleotide sequence variation in mitochondrial Cytochrome Oxidase I and II: congruence with morphological data. Mol. Biol. Evol., 11, 128-141.

DESAlLE, R., FREEDMAN, T., PRAGER, E. M. AND WILSON, A. c. 1987. Tempo and mode of sequence evolution in mitochondrial DNA of Hawaiian Drosophila. J. Mol. Evol., 26, 157-164.

DOYEN, J. T. 1972. Familial and subfamilial classification of the Tenebrionoidea (Coleoptera) and a revised generic classification of the Coniontini (Tentyriidae). Quaest. Entomol., 8, 357-376.

EMERSON, B. C. AND WALlis, G. P. 1995. Phylogenetic relationships of the Prodontria (Coleoptera; Scarabaeidae; subfamily Melolonthine), derived from sequence variation in the mitochondrial cytochrome oxidase II gene. Mol. Phylogen. Evol. (in press).

ESPAÑol, F. 1957a. Los Hegeter de las Canarias Orientales (Col. Tenebrionidae). Trabajos del Museo de Zoología (N. S. Zoológica), 2, 1-16.

ESPAÑol, F. 1957b. Contribución al conocimiento de los Tentyriini de las Canarias Orientales: sobre el pretendido Gen. Pseudotaltophila Reitt. 'EOS' Revista Espanola de Entomología, 33, 157-176.

FELSENSTEIN, J. 1993. PHYLIP (Phylogeny Inference Package). Version 3.5c. University of Washington, Seattle.

FITCH, W. M. AND YE, J. 1991. Weighted parsimony: Does it work? In: Miyamoto, M. M. and Cracraft, J. (eds) Phylogenetic Analysis of DNA Sequences, pp. 147-154. Oxford University Press, Oxford.

FUNK, D. J., FUTUYMA, D. J., ORTI, G. AND MEYER, A. 1995. Mitochondrial DNA sequences and multiple data sets: a phylogenetic study of phytophagous beetles (Chrysomelidae: Ophraella). Mol. Biol. Evol., 12, 627-640.

JUAN, C., OROMI, P. AND HEWITT, G. M. 1995. Mitochondrial DNA phylogeny and sequential colonization of Canary Islands by darkling beetles of the genus Pimelia (Tenebrionidae). Proc. R. Soc. B., 261, 173-180.

KIMURA, M. 1980. A simple method for estimating evolutionary rate of base substitution through comparative studies of nucleotide sequences. J. Mol. Evol., 16, 111-120.

KRAUS, F. AND MIYAMOTO, M. м. 1991. Rapid cladogenesis among Pecoran ruminants: evidence from mitochondrial DNA sequences. Syst. Zool., 40, 117-130.

LI, w.-H. 1993. Unbiased estimation of the rates of synonymous and nonsynonymous substitution. J. Mol. Evol., 36, 96-99.

LI, W.-H., wU, C.-I AND LUO, C.-C. 1985. A new method for estimating synonymous and nonsynonymous rates of nucleotide substitution considering the relative likelihood of nucleotide and codon changes. Mol. Biol. Evol., 2, 150-174.

LIU, H. AND BECKENBACH, A. T. 1992. Evolution of the mitochondrial cytochrome oxidase II gene among 10 orders of insects. Mol. Phylogen. Evol., 1, 41-52.

LUNT, D. H., ZHANG, D.-X., SZYMURA, J. M. AND HEWITT, G. M. 1996. The insect COI gene: evolutionary patterns and conserved primers for phylogenetic studies. Insect Mol. Biol. (in press).

MADDISON W. P. AND MADDISON, D. R. 1992. MACCLADE: Analysis of Phylogeny and Character Evolution. Version 3.1. Sinauer Associates, Sunderland, MA.

OROMI, P. 1982a. Los Tenebriónidos de las Islas Canarias. Instituto de Estudios Canarios, 50 Aniversario, 1, 265-292.

OROMI, P. 1982b. Distribución de los Tenebrionidae (Coleoptera) en las Islas Atlánticas. Boletim Sociedade Portuguesa Entomologia, 7, 215-231.

PAMILO, P. AND NEI, M. 1988. Relationships between gene trees and species trees. Mol. Biol. Evol., 5, 568-583.

SAITOU, N. AND NEI, M. 1987. The Neighbor-Joining method: a new method for reconstructing phylogenetic trees. Mol. Biol. Evol., 4, 406-425.

SARASTE, M. 1990. Structural features of cytochrome oxidase. Q. Rev. Biophys., 23, 331-366.

SARICH, v. M. AND wILSON, A. C. 1967. Rates of albumin evolution in primates. Proc. Natl. Acad. Sci. U.S.A., 58, $142-148$.

SWOFFORD, D. 1993. PAUP: Phylogenetic Analysis Using Parsimony. Version 3.1.1. Smithsonian Institution, Washington DC.

TAMURA, K. 1992. The rate and pattern of nucleotide substitution in Drosophila mitochondrial DNA. Mol. Biol. Evol., 9, 814-825.

THORPE, R. S., MCGREGOR, D. P. AND CUMMING, A. M. 1993. Molecular phylogeny of the Canary Island lacertids (Gallotia): mitochondrial DNA restriction fragment divergence in relation to sequence divergence and geological time. J. Evol. Biol., 6, 725-735.

THORPE, R. S., MCGREGOR, D. P., CUMMING, A. M. AND JORDAN, w. C. 1994. DNA evolution and colonization sequence of island lizards in relation to geological history: mtDNA RFLP, cytochrome B, cytochrome oxidase, 12S rRNA and nuclear RAPD analysis. Evolution, 48, 230-240.

wollaston, t. v. 1864. Catalogue of Canarian Coleoptera. John van Voorst, London.

WU, C.-I AND LI, w.-H. 1985. Evidence for higher rates of nucleotide substitution in rodents than in man. Proc. Natl. Acad. Sci. U.S.A., 82, 1741-1745. 